\title{
Does Emotion Help or Hinder Immediate Memory? Arousal Versus Priority-Binding Mechanisms
}

\author{
Christopher B. Hadley and Donald G. MacKay \\ University of California, Los Angeles
}

\begin{abstract}
People recall taboo words better than neutral words in many experimental contexts. The present rapid serial visual presentation (RSVP) experiments demonstrated this taboo-superiority effect for immediate recall of mixed lists containing taboo and neutral words matched for familiarity, length, and category coherence. Under binding theory (MacKay et al., 2004), taboo superiority reflects an interference effect: Because the emotional reaction system prioritizes binding mechanisms for linking the source of an emotion to its context, taboo words capture the mechanisms for encoding list context in mixed lists, impairing the encoding of adjacent neutral words when RSVP rates are sufficiently rapid. However, for pure or unmixed lists, binding theory predicted no better recall of taboo-only than of neutral-only lists at fast or slow rates. Present results supported this prediction, suggesting that taboo superiority in immediate recall reflects context-specific binding processes, rather than context-free arousal effects, or emotion-linked differences in rehearsal, processing time, output interference, time-based decay, or guessing biases.
\end{abstract}

Keywords: emotion, short-term memory, arousal, binding

How does emotion linked with taboo words impact immediate memory? Recent results indicate two related effects of emotion on immediate recall of rapidly presented rapid serial visual presentation (RSVP) lists containing a mixture of taboo and neutral words (MacKay et al., 2004; MacKay, Hadley, \& Schwartz, in press). One is taboo-superiority: better recall of taboo than of neutral words matched for length and familiarity. The other is poorer recall of neutral words at least one word after a taboo word (the word-after effect) and up to two words before a taboo word (the word-before effect; for related "retrograde amnesia" effects involving other distinctive or emotionally salient stimuli, see Loftus $\&$ Burns, 1982, and Tulving, 1969). The goal of the present study was to further our understanding of immediate memory and emotion by testing alternative explanations of these effects. The two main alternatives were arousal theory (see, e.g., Cahill \& van Stegeren, 2003; Hamann, Ely, Grafton, \& Kilts, 1999; Kensinger, \& Corkin, 2004; Le Doux, 1996, pp. 206-208; Maratos, Allan, \& Rugg, 2000; and Phelps et al., 1998) and the priority-binding assumption of binding theory (see, e.g., MacKay et al., 2004; MacKay et al., in press; see also MacKay, Burke, \& Stewart, 1998; and MacKay, Stewart \& Burke, 1998).

\section{Arousal Theory and the Taboo-superiority Effect}

Arousal theory explains taboo superiority as a facilitation effect. Under the arousal hypothesis tested here, low-level sensory inputs

Christopher B. Hadley and Donald G. MacKay, Psychology Department, University of California, Los Angeles.

The authors gratefully acknowledge support from the Samuel A. MacKay Memorial Research Fund and thank Ronit Menashe, Melissa Murren, and Sam Soleimany for running participants, coding data, and providing general assistance.

Correspondence concerning this article should be addressed to Christopher B. Hadley, Psychology Department, UCLA, Los Angeles, CA 900951563. Email: chadley@psych.ucla.edu directly engage an emotional reaction system (say, the basolateral amygdala) that triggers release of neurotransmitters or endogenous stress hormones (such as epinephrine and cortisol) that facilitate memory consolidation for emotional events that are suprathreshold and not overly traumatic or repression-prone. These amygdalamediated encoding processes enable consolidation of emotional events in a brain region such as the hippocampus so that the brain can achieve memory strength that is directly proportional to memory importance and arousal without interference from other ongoing events or stimulus factors (see, e.g., Cahill \& McGaugh, 1998; Cahill \& van Stegeren, 2003).

Like other emotion-linked stimuli associated with enhanced event recall, taboo words are not repression-prone when presented at suprathreshold rates (see MacKay et al., 2004), and taboo (but not neutral) words induce enhanced skin conductance, an unconscious index of sympathetic nervous system activity and emotional arousal (see, e.g., LaBar \& Phelps, 1998; and Harris, Aycicegi, \& Gleason, 2003). The arousal hypothesis therefore applies to the present tasks: immediate recall of taboo and neutral words presented at varied rates in pure (taboo-only and neutral-only) lists (Experiment 1) and in mixed taboo-neutral lists (Experiment 2). The arousal hypothesis predicted taboo superiority, independent of stimulus factors such as presentation rate and pure- versus mixedlist type in Experiments 1 and 2.

\section{Binding Theory, Priority-binding, and the Taboo-superiority Effect}

Like arousal theory, binding theory applies across a wide range of emotion-linked contexts. However, we will reserve general or task-independent binding theory claims for the General Discussion. Here we focus on applying binding theory to immediate list recall (MacKay \& Burke, 1990) and the taboo-superiority effect (MacKay et al., 2004).

Like other distributed memory theories (e.g., Burgess \& Hitch, 
1999; Howard \& Kahana, 2002), binding theory assumes that list recall depends on the formation of new bindings or associative links between each word in a list and its episodic context, that is, an internal representation of where or when the word occurred, for example, in a particular list or experiment. To recall that a particular word occurred in a particular list under binding theory, people activate the word via its link to the episodic context. However, words are complex stimuli with at least three aspects (phonology, orthography, and semantics), and binding theory specifies precisely what aspect of a word becomes bound to its episodic context during list learning: the lexical node that represents the meaning of the word in the cortex.

Binding theory also specifies the process whereby a lexical node becomes bound to its episodic context: An activated lexical node primes or readies for activation a binding node (located, say, in the hippocampus ${ }^{1}$ ) that specializes in binding two or more general classes of cortical nodes. The general classes of cortical nodes with links to a particular binding node are known as the domain of the binding node, and different binding nodes have different domains. The present study focuses especially on a binding node with two classes of cortical nodes in its domain: nodes representing episodic context and lexical nodes representing taboo words. Under binding theory, activating the binding node with that domain determines whether a taboo word will be linked to its episodic context and recalled following list presentation.

For pure or unmixed lists containing either taboo or neutral words, the processing sequence is as follows: Lexical nodes representing word meaning are activated in the cortex and call up or prime their connected binding node word by word in sequence; each binding node in turn forms a new connection between whatever nodes are currently activated in its domain, here, the classes of cortical nodes representing word meaning and episodic context. However, because binding normally proceeds sequentially one link at a time, and connection formation is a relatively time-consuming process, the time to form a new connection between a lexical node and its episodic context can greatly exceed stimulus duration for rapidly presented stimuli. This means that a word in a long or rapidly presented list will be forgotten or irretrievable if its lexical node is no longer activated when the binding node for forming its link to episodic context is applied.

Because of emotion-linked priority binding, the processing sequence differs somewhat for mixed lists containing both taboo and neutral words. When children first learn a taboo word, a strong link is formed between the lexical node representing the meaning of the taboo word and the system that generates emotional reactions (say, the amygdala). This assumption seems plausible because emotional reactions to taboo words are based on word meaning rather than acoustics, phonology, or orthography; it is word meaning rather than acoustics, phonology, or orthography that makes taboo words taboo and emotionally arousing. By way of illustration, a word such as ask is nonarousing and neutral in emotional tone despite extensive overlap in acoustics, phonology, and orthography with the taboo word ass, and many examples of such low-level overlap between taboo and neutral words could be cited. In short, word meaning triggers emotional reactions in binding theory, unlike in arousal theory, in which sensory- rather than semanticlevel inputs can directly engage the amygdala. However, neutral words lack links to the amygdala for triggering strong emotional reactions under binding theory.

Activating a lexical node therefore engages the binding node system for taboo and neutral words under binding theory, but only taboo words strongly engage the emotional reaction system. This emotional reaction system responds immediately and, via direct amygdala-to-hippocampus links, gains access to the binding nodes that link stimuli to their episodic contexts. The resulting interactions between the amygdala and hippocampus serve to delay the activation of currently primed binding nodes for (less important) neutral stimuli, which only become bound to their episodic context after binding for (more important) emotion-linked stimuli is complete. These emotion-linked adjustments in binding order can only occur for stimuli such as taboo and neutral words that engage different binding nodes: Repeated application of the same type of binding node as in pure taboo-only lists is not subject to prioritization. However, emotion-linked delays in the activation of neutral binding nodes neither speed up the activation of emotion-linked binding nodes nor increase the "binding resources" (e.g., time, energy, or rate of processing) available to emotion-linked stimuli. Nor do emotion-linked delays in the activation of neutral binding nodes reduce the binding resources available to neutral stimuli when their binding nodes are applied. The priority-binding assumption therefore contrasts with other hypotheses in which an emotion-linked stimulus prematurely terminates ongoing encoding of a preceding neutral stimulus (Loftus \& Burns, 1982; MacKay et al., 2004) or in which the time or energy available for binding emotion-linked stimuli trades off with the time or energy for binding neutral stimuli (see Meinhardt \& Pekrun, 2003).

The priority-binding assumption readily explains the two already observed types of interference in mixed lists containing taboo and neutral words: word-before and word-after effects, that is, poorer recall of neutral words before and after taboo words in mixed lists presented at $100 \mathrm{~ms} /$ word (MacKay et al., in press) or $170 \mathrm{~ms} /$ word (MacKay et al., 2004). The word-before effect occurs because priority binding for a taboo word delays activation of the binding node for linking the immediately prior neutral word to its episodic context, and because of the rapid RSVP rate, this neutral word is no longer activated when its binding node is applied. As a result, the link to episodic context necessary for retrieving this "word-before" as part of that particular list cannot be formed at fast presentation rates (200 ms/word or less). Binding priority for a taboo word likewise prevents episodic encoding of the immediately following neutral word with even greater likelihood in rapidly presented lists: By the time that binding processes for the taboo word have been completed and the lower-priority episodic binding node for the neutral "word-before" has been applied, activation of the neutral "word-after" has decayed with high probability, so that when its episodic binding node is finally applied, it cannot form the episodic link necessary for retrieving the wordafter as part of the list.

To summarize, the arousal hypothesis explains taboo superiority as being due to encoding facilitation for taboo words independent of the occurrence of neutral words, whereas the priority-binding assumption explains taboo superiority as being due to interference with the encoding of neutral words before and after taboo words in rapidly presented mixed lists. By extension, binding theory predicted that word-before and word-after effects will cause taboo

\footnotetext{
${ }^{1}$ We assigned different types of nodes to neuroanatomical loci here to allow same-level comparison with arousal theory. However, these hypothetical neuroanatomical assignments are not central to how binding theory functions: Different neuroanatomical assignments would yield the same predictions.
} 
superiority for the rapidly presented lists of randomly intermixed taboo and neutral words in Experiment 2: Taboo words will be more retrievable than neutral words in these lists because prioritybinding enables taboo words to become linked to their episodic context with higher probability than neighboring neutral words.

Experiment 1 tested the "taboo-equality" prediction derived from the priority-binding assumption: There will be no better recall of taboo than of neutral words in pure (unmixed) lists at fast or slow presentation rates because emotion-linked delays in binding only occur for stimuli that engage different types of binding nodes, regardless of presentation rate. As a result, the emotionlinked delays in the binding of neutral words that occur in mixed taboo-neutral lists will not occur in taboo-only lists such as ass dyke piss that involve repeated application of the same type of binding node.

Experiment 1 also tested predictions derived from two subsidiary hypotheses for explaining taboo superiority in mixed lists: the rehearsal hypothesis and the processing time hypothesis. The rehearsal hypothesis applies especially to presentation rates that are slow enough to allow rehearsal, for example, 1,000 ms/word or more. Because people are more likely to rehearse emotional than neutral events (see, e.g., MacKay et al., 2004, for a recent review), taboo superiority may reflect greater rehearsal of taboo than of neutral words presented at 1,000 ms/word. This rehearsal hypothesis predicted greater taboo superiority at the 1,000 ms/word than at the 200ms/word rate in Experiment 1 because $200 \mathrm{~ms} /$ word is too rapid to allow rehearsal (see, e.g., Murdock, 1974, p. 168).

The processing-time hypothesis applies especially to fast rather than to slow presentation rates. Under the processing-time hypothesis, taboo superiority arises because emotion enables faster activation (rather than priority-binding) of emotion-linked words, so that taboo words enjoy surplus encoding time relative to neutral words in pure lists. This longer encoding time (say, tens of milliseconds) is of little consequence at slow presentation rates but can spell the difference between successful versus unsuccessful encoding at rates such as $200 \mathrm{~ms} /$ word. The processing-time hypothesis therefore predicted relatively better recall of taboo than of neutral words at fast rather than slow presentation rates.

\section{Experiment 1}

Experiment 1 compared immediate recall of taboo-only versus neutral-only lists at fast $(200 \mathrm{~ms} /$ word $)$ versus slow $(1,000 \mathrm{~ms} /$ word) RSVP rates. We matched the taboo and neutral words for length and familiarity as in MacKay et al. (2004, in press), and we selected the neutral words from a set of foodstuff- and cookingrelated terms, a restricted semantic category with high category coherence resembling taboo words. We also attempted to equate our taboo and neutral words on factors such as set size, imagery, connotative strength, syntax, and semantic similarity. However, we make no a priori claim that we successfully equated these memory-related factors for the taboo and neutral words and participants in Experiment 1, especially because in the case of taboo words, some of these factors vary as a function of participant gender and sexual orientation (see Jay, 2000, p. 168) and cannot be matched a priori. Instead we will present results that speak post hoc to the success of our stimulus matching procedures.

The arousal hypothesis predicted taboo superiority at both fast and slow presentation rates in Experiment 1. Binding theory predicted taboo equality; that is, no better memory for taboo-only than for neutral-only lists at the slow or fast presentation rates. The rehearsal hypothesis predicted taboo superiority at the slow rate but not at the fast rate. The processing-time hypothesis predicted relatively greater taboo superiority at the fast than at the slow rate.

\section{Method}

\section{Participants}

Participants were 16 University of California, Los Angeles, undergraduates (5 men and 11 women, aged 20-25 years, $M=21.5, S D=1.56$ ), who spoke fluent English, reported normal or corrected-to-normal vision, and received partial course credit or payment of $\$ 5$ for participating. Participants were informed that they might see offensive or taboo words and could have served in another ongoing experiment without taboo words, but none chose that option.

\section{Materials and Design}

The within-subject design was 2 (word type: taboo vs. neutral) $\times 2$ (rate: $200 \mathrm{~ms} /$ word vs. $1,000 \mathrm{~ms} /$ word). The Appendix shows the materials: 68 single-syllable taboo and neutral words matched in pairs for initial consonant and length in letters. The taboo words $(N=34)$ were socially proscribed insults, sexual references, and profanities, and the neutral words $(N=34)$ were foodstuff- or cooking-related words. A group of 27 undergraduates resembling participants in Experiments 1 and 2 rated all 68 words for familiarity and "tabooness" on scales of 1-5 (see MacKay et al., 2004; in press), with mean results shown in the Appendix. Familiarity ratings did not differ for taboo $(M=2.96, S D=.901)$ versus neutral $(M=$ $2.97, S D=.903$ ) words, $t(66)=.047, p=.963$, but obscenity ratings were reliably greater for taboo $(M=3.16, S D=.793)$ than for neutral $(M=$ $1.08, S D=.171)$ words, $t(66)=15.012, p<.001$.

We created experimental lists containing $7,8,9$, or 10 words $^{2}$ by randomly sampling without replacement from the taboo or neutral word sets. We then modified the lists to ensure that adjacent words never formed familiar phrases that could aid recall. Each participant saw and recalled 32 lists: 16 lists (two of each list type and length) at each rate, with order of presentation rates and list types counterbalanced across participants. To equate proactive interference across list type and presentation rate, we arranged for each word to appear only once in each eight-list block, for a total of four repetitions across the eight four-list blocks, with order of list type and list length randomized within each block to discourage the adoption of length-based strategies in recall.

\section{Procedure}

We presented the lists in a 36-point Chicago font using standard RSVP procedures with words centered on the screens of Macintosh G3 computers (Apple Computer, Cupertino, CA) running PsyScope (Cohen, MacWhinney, Flatt, \& Provost, 1993). Verbal and computer-presented instructions called for item recall, in order if possible. To ensure comprehension of the instructions, we showed participants four practice lists containing neutral words from the categories of animals, minerals, or clothing presented at the same rate as the first block of experimental lists. To initiate each trial, participants pressed the space bar, which triggered a 2,000-ms row of asterisks (********), followed by the list, one word at a time, and the recall cue, a row of question marks (?????????). To minimize possible

\footnotetext{
${ }^{2}$ We presented unpredictably varying list lengths in Experiments 1 and 2 to discourage strategies that might impact encoding processes as a function of word type, our primary focus. For example, participants in Experiment 2 who encountered mixed lists with consistent list lengths might focus on the relation between a word and its serial position, a strategy that would diminish our ability to detect recall differences due to word type in mixed lists with serial positions equated across word type.
} 
biases against reporting taboo words, the experimenter left the room during the experiment proper, and participants wrote their immediate recall responses on a numbered sheet, inserting their anonymous answer sheets into a sealed "mailbox" after the last list.

After half of the experimental lists, participants were told that the remaining lists had a faster or slower rate than the preceding lists. Participants then received four practice trials to become familiar with the new rate, and the remaining experimental trials proceeded in the same manner as before.

\section{Results and Discussion}

All analyses involved item rather than order recall. Figure 1 (left panel) shows the mean proportion of taboo and neutral words recalled as a function of presentation rate. A 2 (rate: fast vs. slow) $\times 2$ (word type: taboo vs. neutral) analysis of variance (ANOVA) on these data yielded a main effect of rate, $F(1,15)=$ $45.121, M S E=1.418, p<.001$, with better recall at the slow $(M=.526, S D=.088)$ than at the fast $(M=.399, S D=.076)$ rate, but no effect of word type, $F<1$, and no Rate $\times$ Word Type interaction, $F<1$. The null effect of word type suggests that our taboo and neutral words did not differ overall in factors that influence memory. Overall differences in recall that might arise from failure to control memory-linked factors such as set size, category coherence, imagery, connotation, syntax, and within-category semantic similarity (see, e.g., Bourassa \& Besner, 1994; Poirier \& Saint-Aubin, 1995; Walker \& Hulme, 1999) did not emerge.

Present results comported with predictions derived from the priority-binding assumption of binding theory: no better memory for taboo-only than for neutral-only lists at slow or rapid presentation rates. However, present results did not support the remaining three hypotheses: Contrary to the arousal hypothesis, recall was no better for taboo than for neutral words at either presentation rate; contrary to the rehearsal hypothesis, recall was no better for taboo than for neutral words at the slow rate; and contrary to the processing-time hypothesis, recall was no better for taboo than for neutral words at the fast rate.

\section{Subsidiary Results}

To test for possible gender-linked effects of emotion (see, e.g., Cahill \& van Stegeren, 2003), we analyzed mean recall in a 2

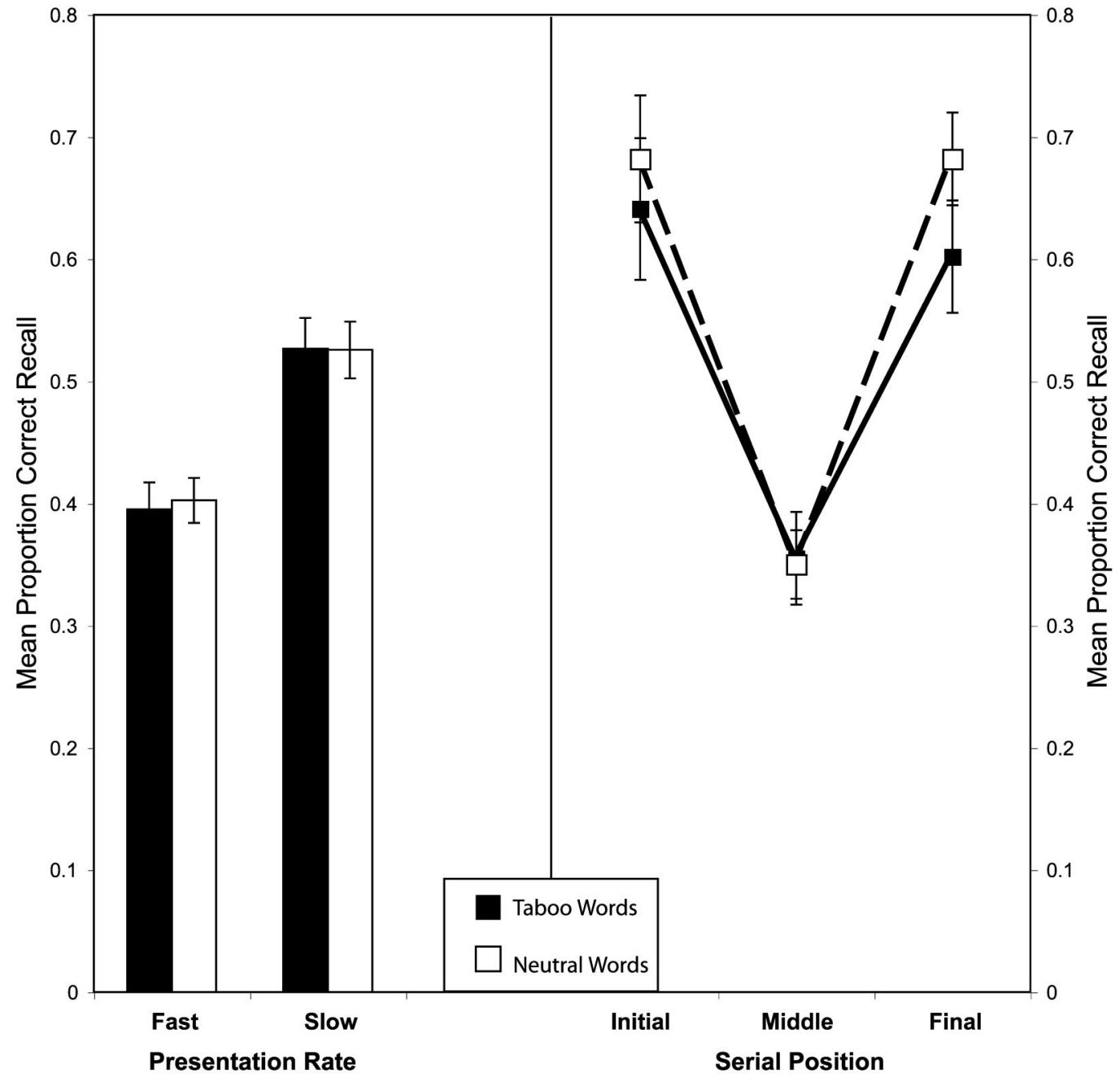

Figure 1. Mean proportion of correct recall in Experiment 1 for taboo words (in black) versus neutral words (in white) as a function of presentation rate (left panel) and list position (right panel). Error bars indicate \pm 1 SEM. 
(participant gender: female vs. male) $\times 2$ (word type: taboo vs. neutral) ANOVA. The results replicated the word type results for our main ANOVA, with no main effect of gender and no Gender $\times$ Word Type interaction, both $F \mathrm{~S}<1$. This indicates that the present results were unrelated to participant gender.

To test whether proactive interference differed for taboo-only versus neutral-only lists, we scored intrusion errors by word type for Block 1 (the first eight lists) versus Block 4 (the last eight lists). A 2 (word type: taboo vs. neutral) $\times 2$ (block: 1 vs. 4) ANOVA on these data yielded a marginal effect of block, $F(1,15)=3.581$, $M S E=.030, p=.078$, with more intrusions per list in Block 4 $(M=.230, S D=.192)$ than in Block $1(M=.148, S D=.116)$, but no interaction between word type and block, $F(1,15)=1.461$, $M S E=.028, p=.245$, and no effect of word type, $F(1,15)=$ $2.483, M S E=.022, p=.136$, indicating no difference in proactive interference for taboo versus neutral lists.

To test whether serial position effects differed for taboo-only versus neutral-only lists, we compared mean correct recall for the initial, middle, and last words in the lists (see Figure 1, right panel). ${ }^{3}$ A 2 (word type: taboo vs. neutral) $\times 3$ (position: first, middle, or last) ANOVA on these data yielded the usual main effect of serial position, $F(2,30)=15.998, M S E=.060, p<.001$, but no effect of word type, $F(1,15)=2.951, M S E=.0124, p=$ .106 , and no Word Type $\times$ Position interaction, $F(2,30)=1.987$, $M S E=.075, p=.155$, indicating that serial-position effects did not differ for taboo versus neutral lists.

\section{Experiment 2}

Experiment 2 used a 2 (list-type: pure vs. mixed) $\times 2$ (word type: taboo vs. neutral) design to test contrasting theoretical predictions for immediate recall of Experiment 1 words presented at $200 \mathrm{~ms} /$ word. We selected this rapid (200 ms/word) rate for two reasons. One was to rule out rehearsal strategies (see Murdock, 1974, p. 168). Because distinctive word categories in mixed lists tend to be selectively rehearsed (see Rundus, 1971), ruling out rehearsal strategies was essential to ensure that participants did not selectively rehearse taboo words at the expense of neutral words in the mixed-list condition in Experiment 2. Our second reason for choosing the $200 \mathrm{~ms} /$ word rate was theory-based: Binding theory only predicts poorer recall of neutral words in mixed lists with fast RSVP rates. With slow RSVP rates, for example, 2,000 ms/word, taboo words can facilitate rather than interfere with recall of neutral neighbors under binding theory. The reason is that slow presentation rates enable two types of emotion-linked binding: concurrent-context binding and sequential-context binding. Concurrent-context binding (the only type of episodic binding discussed so far) governs recall that a particular word occurred in a particular experiment- or list-context. By contrast, sequentialcontext binding governs recall that a particular word immediately follows one word and precedes another in the list.

We illustrate this slow-rate facilitation prediction of binding theory using a hypothetical example: a three-word mixed list, $\mathrm{AXB}$, in which $\mathrm{X}$ is a taboo word and $\mathrm{A}$ and $\mathrm{B}$ are neutral neighbors, presented at some relatively slow rate. By assumption, this rate of, say, $1,000 \mathrm{~ms} /$ word enables not only concurrentcontext or episodic binding of $\mathrm{X}$, but sequential-context binding to represent the fact that $\mathrm{X}$ follows $\mathrm{A}$ and precedes $\mathrm{B}$ in the $\mathrm{AXB}$ sequence. These sequential-context links to $\mathrm{X}$ will provide distinctive and redundant retrieval links for the neutral neighbors $A B$, which will enable better recall of neutral words in mixed than pure lists at this relatively slow rate.

The distinction between concurrent and sequential context helps clarify why emotion-linked priority-binding delays (and thereby prevents) episodic encoding of neutral stimuli at rapid presentation rates without simultaneously facilitating episodic encoding of emotion-linked stimuli. Delayed encoding of temporally adjacent neutral stimuli normally guarantees encoding of important emotion-linked stimuli for concurrent and sequential contexts, including sequential relations with neutral neighbors. This also normally guarantees that neutral neighbors become encoded in relation to the emotional stimulus rather than or in addition to the more general concurrent-context (e.g., occurrence in a particular experiment). However, rapid RSVP presentation prevents the encoding of emotion-linked stimuli for sequential context and often prevents the encoding of neutral neighbors for either sequential or concurrent context.

The priority-binding assumption generated two sets of predictions for Experiment 2. One involved a Word Type $\times$ List Type interaction, with taboo superiority in the mixed lists (replicating MacKay et al., 2004, and in press), but not in the pure lists (replicating Experiment 1 results). The second set of prioritybinding predictions involved a main effect of word type, with better overall recall of taboo than neutral words, and a main effect of list type, with better overall recall in the pure than mixed lists. The reason is that taboo superiority reflects interference in mixed lists under the binding-priority assumption, with worse recall of neutral words in mixed than in pure lists, but equivalent recall of taboo words in pure and mixed lists, and equivalent recall of taboo and neutral words in pure lists, yielding overall main effects for word type and list type.

To illustrate how the priority-binding assumption generates these predictions, we describe the hypothetical encoding processes in three four-word lists presented at $200 \mathrm{~ms} /$ word: a pure-taboo list, WXYZ; a pure-neutral list, $\mathrm{ABCD}$; and a mixed taboo-neutral list, $\mathrm{ABYC}$, in which $\mathrm{Y}$ is a taboo word and $\mathrm{A}, \mathrm{B}$ and $\mathrm{C}$ are neutral neighbors. For the pure-taboo list, WXYZ, each taboo word triggers its concurrent-context binding node without delay and the same is true for taboo word $\mathrm{Y}$ in the mixed list, $\mathrm{ABYC}$, and for neutral word B in the pure-neutral list, $\mathrm{ABCD}$. However, neutral word $\mathrm{B}$ does not trigger its concurrent-context binding node without delay in the mixed taboo-neutral list ABYC: An inhibitory amygdala-to-hippocampus interaction triggered by taboo word $\mathrm{Y}$ delays application of the concurrent-context binding node for $\mathrm{B}$ until binding processes for $\mathrm{Y}$ have been completed. Recall of neutral word $\mathrm{B}$ therefore suffers in list $\mathrm{ABYC}$ because its concurrent-context or episodic binding begins later than in pureneutral list $\mathrm{ABCD}$, increasing the chances of binding failure by reducing the probability that its lexical node is still activated when its binding node is applied. In short, neutral word B is better recalled in the pure than in the mixed list, but taboo word $\mathrm{Y}$ is recalled no better in the mixed than in the pure list and no better than neutral word B in the pure-neutral list.

Experiment 2 also tested the faster-binding hypothesis, the assumption that emotion enables faster binding (rather than prioritybinding) of emotion-linked events in otherwise neutral contexts.

\footnotetext{
${ }^{3}$ The middle word was the middle word in odd-length lists but the mean of the two middle words in even-length lists.
} 
Table 1

Example of List Variants for a Seven-word List

\begin{tabular}{llllllll}
\hline \multicolumn{1}{c}{ List type } & Word 1 & Word 2 & Word 3 & Word 4 & Word 5 & Word 6 & Word 7 \\
\hline Pure neutral & cook & snack & chef & jam & wheat & plate & steak \\
Pure taboo & cunt & snatch & clit & jizz & whore & prick & suck \\
Mixed neutral & cunt & snack & chef & jam & whore & prick & steak \\
Mixed taboo & cook & snatch & clit & jizz & wheat & plate & suck \\
\hline
\end{tabular}

Note. Neutral versions of odd-list-length mixed lists have one more neutral than taboo words, whereas taboo versions of odd-list-length mixed lists have one more taboo than neutral words. Taboo words are in italics.

Under the faster-binding hypothesis, taboo words become bound to their episodic context faster than neutral words in mixed lists. As a consequence, neutral words enjoy more (leftover) binding time under the faster-binding hypothesis, enabling superior recall of neutral words in mixed than pure lists, especially for the fast (200 ms/word) presentation rate in Experiment 2.

Another set of theoretical predictions for Experiment 2 was derived from the "resource trade-off" hypothesis of Meinhardt and Pekrun (2003): that events linked to negative emotions receive higher processing priority and thereby drain off all other taskrelated processing resources in zero-sum fashion. This zero-sum hypothesis predicted a Word Type $\times$ List Type interaction with better recall of taboo words in mixed than in pure lists and better recall of neutral words in pure than in mixed lists. The hypothesis that an emotion-linked stimulus benefits by prematurely cutting ongoing encoding of a preceding neutral stimulus predicted this same outcome (Loftus \& Burns, 1982; MacKay et al., 2004), as did the hypothesis that the time or energy available for binding taboo words trades off with the time or energy for binding neutral words in mixed lists.

We illustrate predictions derived from one of these resource trade-off hypotheses using the same hypothetical lists as for binding theory: WXYZ, a pure-taboo list, and ABYC, a mixed tabooneutral list containing taboo word $\mathrm{Y}$ and neutral words ABC. For the pure-taboo list, WXYZ, each taboo word must wait in line for the binding mechanisms until binding for the preceding taboo word is complete. However, for the mixed list, $\mathrm{ABYC}$, binding priority for taboo word $\mathrm{Y}$ enables binding of $\mathrm{Y}$ to begin before binding of $\mathrm{B}$ is complete. Recall of neutral word $\mathrm{B}$ therefore suffers from prematurely terminated binding, and recall of the taboo word $\mathrm{Y}$ benefits because its binding process begins earlier than in the pure-taboo list WXYZ, increasing the chances of successful binding by increasing the probability that its lexical node is still activated when its binding node is applied. In short, taboo word $\mathrm{Y}$ will be better recalled in the mixed than pure list and neutral word $\mathrm{B}$ will be better recalled in the pure than mixed list.

Beyond testing these contrasting theoretical predictions, Experiment 2 had several subsidiary goals. One was to test for the null results predicted under binding theory using greater power than Experiment $1 .^{4}$ Another subsidiary goal was to replicate taboosuperiority effects using better mixed-list stimuli than earlier studies. For example, MacKay et al. (2004; in press) equated taboo and neutral words for familiarity and length, but not for memory-linked factors such as set-size, category-coherence, imagery, connotative strength, syntax, and within-category semantic similarity (see, e.g., Bourassa \& Besner, 1994; Poirier \& Saint-Aubin, 1995; and Walker \& Hulme, 1999). If such factors provided the basis for taboo superiority in MacKay et al. (2004; in press), Experiment 2 should yield taboo-equivalence (no reliable difference in recall of taboo vs. neutral words) because memory-linked factors were effectively controlled in Experiment 2 stimuli (see Experiment 1 results).

\section{Method}

\section{Participants}

Participants were 28 undergraduates $(10$ men and 18 women, aged $18-25, M=19.8$ years, $S D=1.91$ ) resembling Experiment 1 participants.

\section{Materials and Design}

Using the taboo and neutral words in the Appendix, we formed 8 pure taboo and 8 pure neutral lists as in Experiment 1, and 16 mixed (tabooneutral) lists by replacing 3-5 words in unpredictable list-positions in a pure list with words of the opposite type matched for length, initial consonant, and mean list-position. To ensure that each participant saw equal numbers of taboo and neutral words across Experiment 2, half of the 7-word and 9-word lists had one extra neutral word, and the remaining half had one extra taboo word (see Table 1 for variants of an example 7-word list).

\section{Procedure}

Experimental and data analysis procedures resembled those in Experiment 1 except that all lists were presented at $200 \mathrm{~ms} /$ word.

\section{Results and Discussion}

Figure 2 (left panel) shows the mean proportion of words recalled as a function of list and word type. A 2 (word type: taboo vs. neutral) x 2 (list type: pure vs. mixed) ANOVA on these data yielded a main effect of word type, $F(1,27)=10.668, M S E=$ $.045, p=.003$, with better overall recall of taboo than of neutral words, a main effect of list type, $F(1,27)=18.257, M S E=.002$, $p<.001$, with better recall in pure than in mixed lists, and a Word Type $\times$ List Type interaction, $F(1,27)=22.529, M S E=.003$, $p<.001$, because of superior recall of taboo versus neutral words in mixed lists, $t(27)=5.129, p<.001$, but not in pure lists, $t(27)=1.178, p=.250$.

Planned comparisons also yielded superior recall of neutral words in pure $(M=0.45, S D=.058)$ versus mixed $(M=0.36$,

\footnotetext{
${ }^{4}$ Post hoc analyses indicated that power for the pure lists in Experiment 1 was .73 to detect an effect of word type as large as that for the mixed lists in Experiment $2\left(\eta_{p}{ }^{2}=.467\right)$. By contrast, power for the pure lists in Experiment 2 was .93 to detect an effect of the same size (i.e., much greater than the common power standard of .80).
} 


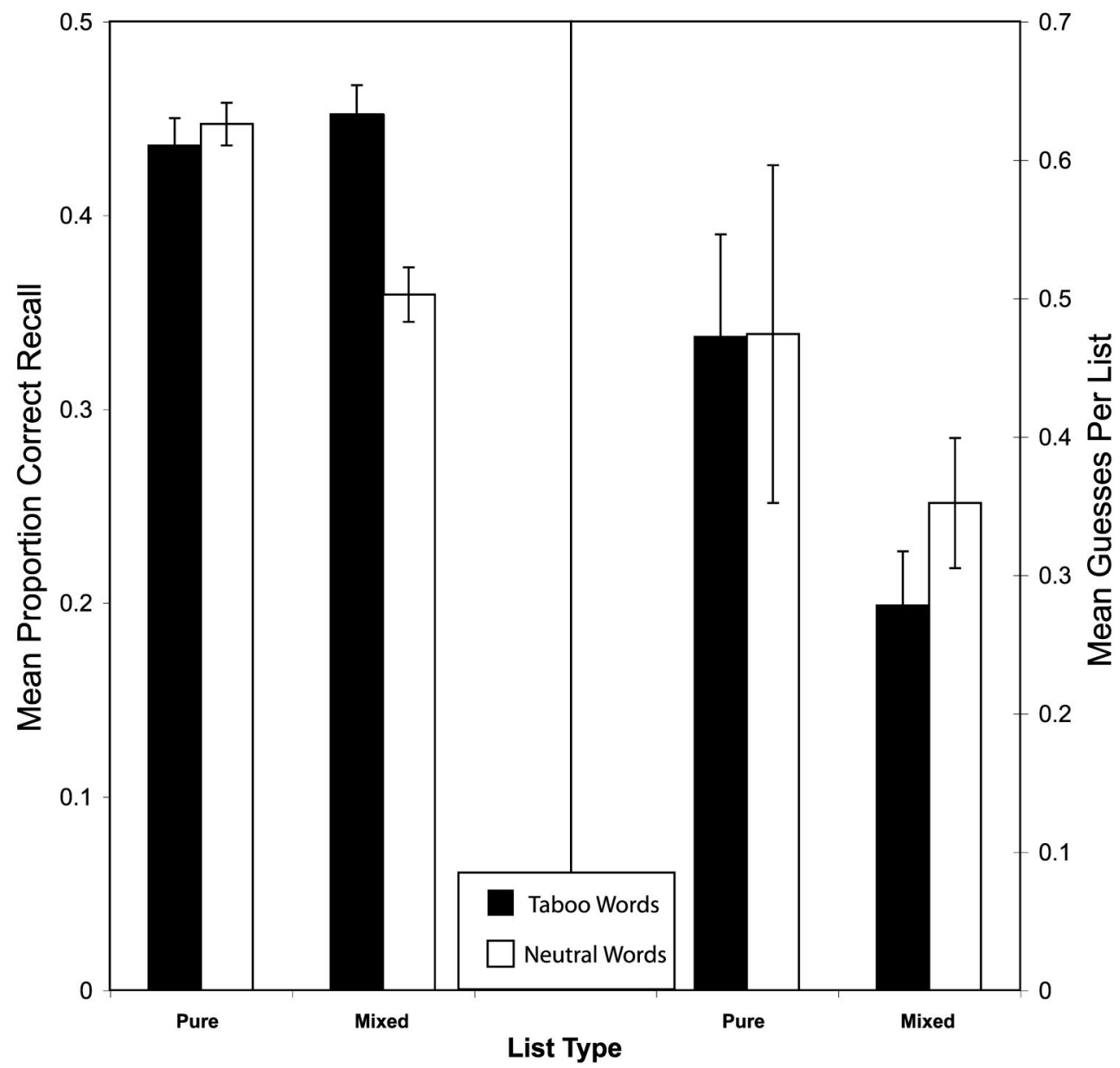

Figure 2. Mean proportion of correct recall in Experiment 2 for taboo words (black bars) versus neutral words (white bars) as a function of list type (left panel), together with the mean proportion of guesses (right panel). Error bars indicate \pm 1 SEM.

$S D=.073)$ lists, $t(27)=7.570, p<.001$, but no difference in recall of taboo words in pure $(M=0.44, S D=.072)$ versus mixed $(M=0.45, S D=.080)$ lists, $t(27)=-1.091, p=.285$. A more sensitive analysis that omitted initial and final words in the lists to remove potential ceiling effects also yielded no difference in recall of taboo words in pure $(M=0.374, S D=.086)$ versus mixed $(M=0.398, S D=.99)$ lists, $t(27)=-1.372, p=.181$.

Present results supported the predictions derived from binding theory and the priority-binding assumption: that taboo superiority in immediate recall of rapidly presented mixed lists reflects an interference effect, with worse recall of neutral words in mixed than in pure lists but equivalent recall of taboo words in pure and mixed lists and equivalent recall of taboo and neutral words in pure lists, yielding a Word-Type $\times$ List-Type interaction with overall main effects for word type and list type.

Present results did not support the resource priority hypothesis of Meinhardt and Pekrun (2003): that events linked to negative emotions achieve higher processing priority and thereby drain off all other task-related processing resources in zero-sum fashion. Contrary to this zero-sum hypothesis, taboo words were recalled no better in mixed than in pure lists even though neutral words were recalled better in pure than in mixed lists. This same result also contradicted two other resource trade-off hypotheses. One is that emotion-linked stimuli benefit by prematurely cutting off the encoding of preceding neutral stimuli. The other is that the time or energy available for binding taboo words trades off with the time or energy available for binding neutral words in mixed lists.

Present results also failed to support the faster-binding assumption that emotion enables faster binding (rather than prioritybinding) of emotion-linked events. The faster-binding hypothesis predicted superior recall of neutral words in mixed than in pure lists, the opposite of Experiment 2 results.

\section{Subsidiary Results}

We again tested for gender-linked effects of emotion using a 2 (participant gender: female vs. male) $\times 2$ (word type: taboo vs. neutral) ANOVA and replicated the word type results for our main ANOVA, with no main effect of gender, $F<1$, and no Gender $\times$ Word Type interaction, $F(1,26)=1.276, M S E=.0045, p=.269$. This indicates that the present results were unrelated to participant gender.

To test whether taboo superiority in mixed lists reflects a general bias toward reporting taboo rather than neutral words, we 
analyzed guesses or reports of words not from the list presented. Figure 2 (right panel) shows the mean number of taboo versus neutral guesses per list, and a 2 (word type: taboo vs. neutral) $\times 2$ (list type: mixed vs. pure) ANOVA on these data yielded a list-type effect, $F(1,27)=18.126, M S E=.037, p<.001$, with more guesses for pure than for mixed lists, but no word type effect, $F<1$, and no Word Type $\times$ List Type interaction, $F<1$. Present results do not therefore indicate a reporting bias favoring taboo over neutral words in mixed lists.

To test whether taboo superiority reflects greater output interference or time-based decay for neutral than for taboo words in mixed lists, we computed output position (serial position in recall) as a function of word type. Mean output position did not differ for taboo $(M=2.34, S D=.314)$ versus neutral $(M=2.35, S D=$ .326) words, $t(27)=-.163, p=.871$, indicating no tendency to recall taboo words before neutral words so as to yield greater output interference or time-based decay for neutral words in mixed lists.

\section{General Discussion}

The present taboo-superiority effects are difficult to explain under the arousal hypothesis outlined in the introduction. Contrary to the arousal hypothesis, taboo superiority does not result from a process that simply facilitates the encoding of taboo words: Taboo superiority only occurred in rapidly presented mixed lists and reflected interference with the encoding of neutral words due to prior or subsequent occurrence of taboo words. Taboo superiority failed to occur for pure (taboo-only and neutral-only) lists in Experiments 1 and 2, which suggests that amygdala-triggered encoding processes did not directly facilitate memory traces for taboo words. The poorer recall of neutral words before and after taboo words in rapidly presented mixed lists (the word-before and word-after effects; see MacKay et al., 2004, Experiment 4) is likewise problematic for the arousal hypothesis, as are the data indicating word-specific emotional reactions to taboo words in MacKay et al. (Experiments 1 and 2): If taboo words only trigger nonspecific emotional responses such as arousal, word-specific emotional reactions to taboo words would not be expected.

Also problematic for the arousal hypothesis outlined in the introduction is the finding that mixed-list taboo superiority in Experiment 2 involved links to word meaning rather than to low-level sensory features. The reason was outlined earlier: Word meaning - not acoustics, phonology, or orthography-makes taboo words taboo and emotionally arousing. Moreover, effects of word meaning in immediate recall of taboo words suggest that, in general, episodic links to lexical nodes determine the recall of words in lists.

Of course, present meaning-linked effects only rule out the arousal hypothesis assumption that taboo words engage a "fast" or low-level pathway to the amygdala. Present results do not rule out a fast low-level amygdala pathway for other (nonlinguistic) emotional stimuli. Moreover, arousal theory postulates a second cortex-to-amygdala pathway (see Le Doux, 1996, p. 211) that comports with the present results if this "slow pathway" includes the binding theory links between lexical nodes and the amygdala.

Consider now the subsidiary hypotheses for explaining taboo superiority noted earlier. Present results ruled out accounts of taboo superiority based on emotion-linked rehearsal, output interference, time-based decay, and guessing biases. Also ruled out were differences between taboo and neutral words in memorylinked factors such as familiarity, length, serial position effects, set size, category coherence, imagery, connotative strength, syntax, or within-category semantic similarity that might give taboo words an overall advantage in recall. Moreover, present results suggest that failure to control these memory-linked factors was not the basis for taboo superiority in previous mixed-list studies (e.g., MacKay et al., 2004, in press).

Present results also ruled out enhanced processing time for taboo words as the basis for taboo-superiority. Contrary to the processing time hypothesis, taboo words were no better recalled than were neutral words in pure lists with fast RSVP rates in Experiments 1 and 2. Nor was taboo superiority due to faster binding of taboo words to their episodic context in Experiment 2. This faster-binding hypothesis predicted better recall of neutral words in mixed than in pure lists presented at $200 \mathrm{~ms} /$ word, the opposite of Experiment 2 results: poorer recall of neutral words in mixed than in pure lists. Likewise difficult to explain in terms of faster-binding is taboo-equivalence in rapidly presented pure lists (Experiments 1 and 2).

We turn now to the second major account of taboo superiority outlined in the introduction: binding theory and the prioritybinding assumption. Consistent with the main prediction of the priority-binding assumption in binding theory, word type interacted with list type in Experiment 2, yielding taboo superiority in mixed but not in pure lists. The poorer recall of neutral words in mixed than in pure lists also comports with priority-binding prediction. This interference effect supports the priority-binding claim that the lexical node for a taboo word triggers an emotional reaction that delays the binding of episodic context for neutral neighbors, thereby impairing their encoding in rapidly presented lists containing taboo and neutral words. As noted in the introduction, the word-before and word-after effects demonstrated in MacKay et al. (2004, in press) likewise indicate impaired encoding of neutral neighbors due to emotion-linked priority-binding. ${ }^{5}$ Also consistent with priority-binding prediction, overall recall was better in pure than in mixed lists in Experiment 2. However, we note that other factors may also contribute to overall superior recall in pure than mixed lists (see, e.g., Poirier \& Saint-Aubin, 1995).

It is important to distinguish binding theory and the prioritybinding assumption from seemingly similar hypotheses such as that of Meinhardt and Pekrun (2003), in which after receiving processing priority, an emotion-linked stimulus drains off processing resources from its neighbors in zero sum fashion. Unlike this zero-sum resource priority hypothesis, binding resources (e.g., time, energy, or rate of processing) are not enhanced for taboo words and reduced for their neutral neighbors under the binding theory. Although concurrent-context binding is delayed for neutral neighbors under the binding theory, a taboo word receives the same binding resources regardless of context, so that under the

\footnotetext{
5 Although the design of mixed lists in Experiment 2 (see Table 1) made detailed analysis of specific word-before and word-after effects impractical, we have no reason to doubt that list-wide taboo superiority reflects the specific word-before and word-after effects postulated in binding theory: Because taboo and neutral words in our mixed lists were randomly intermixed, almost all neutral words either preceded or followed taboo words in mixed lists.
} 
binding theory, taboo words are no better recalled in mixed than in pure lists.

Now we present some caveats: We stress that the present priority-binding predictions apply only to mixed lists presented at rapid RSVP rates, for example, $200 \mathrm{~ms} /$ word or faster (see the introduction to Experiment 2). We also stress that priority-binding predictions apply only to events that trigger strong emotional reactions, for example, taboo words. This strong-reaction factor may explain why "emotional-superiority" effects using "emotional" words such as fright, fear, death, or war have been small, fragile (task- and context-sensitive), and difficult to replicate (see Dewhurst \& Parry, 2000; Maratos et al., 2000; Talmi \& Moscovitz, 2004). Such words may not arouse emotional reactions that are strong enough to exceed the threshold required to modulate binding priority (see the results of Canli, Zhao, Brewer, Gabrieli, \& Cahill, 2000). Moreover, emotional reactions to words such as death or war may not be sufficiently consistent across participants to yield robust effects resembling taboo superiority in Experiment 2. For example, despite symbolizing something negative for some (but not all) people, the word war is central to the personal concerns of relatively few people (an important factor; see Reiman $\&$ McNally, 1995), and for those few, emotional reactions may be relatively weak because factual and nonemotional references to war are both common and readily imagined.

Finally, we stress that emotion-linked priority-binding may or may not be the basis for taboo-superiority effects observed in some earlier tasks using brief intertrial intervals. An example is found in MacKay et al.'s study (2004, Experiment 5) in which a surprisefree recall test following timed lexical decisions to taboo and neutral words yielded taboo superiority in recall with no difference in processing times for taboo versus neutral words (see also Kensinger \& Corkin, 2003, Experiments 3 and 5). These studies only included mixed lists rather than the taboo-only and neutralonly lists required to distinguish between neutral interference versus taboo facilitation as the basis for taboo superiority in recall. Moreover, interference with neutral stimuli due to priority binding is almost certainly not the basis for taboo superiority in prior taboo Stroop tasks, in which taboo words were better remembered than neutral words in surprise memory tests following color-naming and in which font colors (MacKay et al., 2004, Experiment 3; see also Doerksen \& Shimamura, 2001) and screen locations (MacKay \& Ahmetzanov, 2005) were better remembered when consistently associated with taboo than neutral words (with controls for category coherence, color name learning, set size of the stimuli and responses, and attentional disengagement processes). These mixed-list taboo Stroop studies observed longer processing times for taboo than for neutral words, whereas the opposite pattern would be expected, given priority-binding interference with neutral stimuli, that is, longer processing times for neutral than for taboo words.

We conclude with a more general binding theory proposition that incorporates the priority-binding assumption and applies to emotion-linked stimuli other than taboo words and list recall. Under the binding theory, conceptual representations of emotionlinked stimuli engage an emotional reaction system that prioritizes the activation of binding nodes for linking the source of the emotion to salient aspects of both sequential and concurrent contexts, including the color and spatial location of the stimulus (see, e.g., Doerksen \& Shimamura, 2001; MacKay et al., 2004; and MacKay \& Ahmetzanov, 2005).

\section{References}

Bourassa, D., \& Besner, D. (1994). Beyond the articulatory loop: A semantic contribution to serial order recall of subspan lists. Psychological Bulletin \& Review, 1, 122-125.

Burgess, N., \& Hitch, G. J. (1999). Memory for serial order: A network model of the phonological loop and its timing. Psychological Review, 106, 551-581.

Cahill, L., \& McGaugh, J. L. (1998). Mechanisms of emotional arousal and lasting declarative memory. Trends in Neuroscience, 21, 294-299.

Cahill, L., \& van Stegeren, A. (2003). Sex-related impairment of memory for emotional events with beta-adrenergic blockade. Neurobiology of Learning and Memory, 79, 81-88.

Canli, T., Zhao, Z, Brewer, J., Gabrieli, J. D. E., \& Cahill, L. (2000, October 1). Event-related activation in the human amygdala associates with later memory for individual emotional response. Journal of Neuroscience, 20, RC99.

Cohen, J. D., MacWhinney, B., Flatt, M., \& Provost, J. (1993). PsyScope: A new graphic interactive environment for designing psychology experiments. Behavioral Research Methods, Instruments, and Computers, 25, 257-271.

Dewhurst, S. A., \& Parry, L. A. (2000). Emotionality, distinctiveness, and recollective experience. European Journal of Cognitive Psychology, 12, $541-551$.

Doerksen, S., \& Shimamura, A. P. (2001). Source memory enhancement for emotional words. Emotion, 1, 5-11.

Hamann, S. B., Ely, T. D., Grafton, S. T., \& Kilts, C. D. (1999). Amygdala activity related to enhanced memory for pleasant and aversive stimuli. Nature Neuroscience, 2, 289-293.

Harris, C. L., Aycicegi, A., \& Gleason, J. B. (2003). Taboo words and reprimands elicit greater autonomic reactivity in a first language than in a second language. Applied Psycholinguistics, 24, 561-579.

Howard, M., \& Kahna, M. J. (2002). A distributed representation of temporal context. Journal of Mathematical Psychology, 46, 269-299.

Jay, T. B. (2000). Why we curse: A neuro-psycho-social theory of speech. Philadelphia: John Benjamins.

Kensinger, E. A., \& Corkin, S. (2003). Memory enhancement for emotional words: Are emotional words more vividly remembered than neutral words? Memory \& Cognition, 31, 1169-1180.

Kensinger, E. A., \& Corkin, S. (2004). Two routes to emotional memory: Distinct neural processes for valence and arousal. Proceedings of the National Academy of Sciences, USA, 101, 3310-3315.

LaBar, K. S., \& Phelps, E. A. (1998). Arousal-mediated memory consolidation: Role of the medial temporal lobe in humans. Psychological Science, 9, 490-493.

Le Doux, J. (1996). The emotional brain. New York: Simon \& Schuster.

Loftus, E. F., \& Burns, T. E. (1982). Mental shock can produce retrograde amnesia. Memory \& Cognition, 10, 318-323.

MacKay, D. G., \& Ahmetzanov, M., V. (2005). Emotion, memory, and attention in the taboo Stroop paradigm: An experimental analog of flashbulb memories. Psychological Science, 16, 25-32.

MacKay, D. G., \& Burke, D. M. (1990). Cognition and aging: A theory of new learning and the use of old connections. In T. Hess (Ed.), Aging and cognition: Knowledge organization and utilization (pp. 213-263). Amsterdam: North-Holland.

MacKay, D. G., Burke, D. M., \& Stewart, R. (1998). H. M.'s language production deficits: Implications for relations between memory, semantic binding, and the hippocampal system. Journal of Memory and Language, 38, 28-69.

MacKay, D. G., Hadley, C. B., \& Schwartz, J. H. (in press). Relations between emotion, illusory word perception, and orthographic repetition blindness: Tests of binding theory. Quarterly Journal of Experimental Psychology.

MacKay, D. G., Shafto, M., Taylor, J. K., Marian, D. E., Abrams, L., \& 
Dyer, J. R. (2004). Relations between emotion, memory, and attention: Evidence from taboo Stroop, lexical decision, and immediate memory tasks. Memory \& Cognition, 32, 474-488.

MacKay, D. G., Stewart, R., \& Burke, D. M. (1998). H. M. revisited: Relations between language comprehension, memory, and the hippocampal system. Journal of Cognitive Neuroscience, 10, 377-394.

Maratos, E. J., Allan, K., \& Rugg, M. D. (2000). Recognition memory for emotionally negative and neutral words: An ERP study. Neuropsychologia, 38, 1452-1465.

Meinhardt, J., \& Pekrun, R. (2003). Attentional resource allocation to emotional events: An ERP study. Cognition \& Emotion, 17, 477-500.

Murdock, B. B. (1974). Human memory: Theory and data. Potomac, MD: Erlbaum.

Phelps, E. A., Labar, K. S., Anderson, A. K., O’Connor, K. J., Fulbright, R. K., Spencer, D. D. (1998). Specifying the contributions of the human amygdala to emotional memory: A case study. Neurocase, 4, 527-540.
Poirier, M. \& Saint-Aubin, J. (1995). Memory for related and unrelated words: Further evidence on the influence of semantic factors in immediate serial recall. Quarterly Journal of Experimental Psychology, 48A, 384-404.

Reiman, B. C., \& McNally, R. J. (1995). Cognitive processing of personally relevant information. Cognition and Emotion, 9, 325-340.

Rundus, D. (1971). Analysis of rehearsal processes in free recall. Journal of Experimental Psychology, 89, 63-77.

Talmi, D., \& Moscovitz, M. (2004). Can semantic-relatedness explain the enhancement of memory for emotional words? Memory \& Cognition, $32,742-751$.

Tulving, E. (1969). Retrograde amnesia in free recall. Science, 164, 88-90. Walker, I., \& Hulme, C. (1999). Concrete words are easier to recall than abstract words: Evidence for a semantic contribution to short-term serial recall. Journal of Experimental Psychology: Learning, Memory, and Cognition, 25, 1256-1271.

\section{Appendix}

Length, Familiarity, and "Tabooness" Ratings for the Taboo and Neutral Words Used in Experiments 1 and 2

\begin{tabular}{|c|c|c|c|c|c|c|c|c|c|c|c|}
\hline $\begin{array}{l}\text { Taboo } \\
\text { words }\end{array}$ & Length & Familiarity & $\mathrm{SD}$ & Tabooness & $\mathrm{SD}$ & $\begin{array}{c}\text { Neutral } \\
\text { words }\end{array}$ & Length & Familiarity & $\mathrm{SD}$ & Tabooness & $\mathrm{SD}$ \\
\hline ass & 3 & 4.15 & 0.73 & 3.31 & 0.93 & ale & 3 & 1.92 & 1.06 & 1.42 & 0.70 \\
\hline balls & 5 & 3.69 & 1.12 & 2.46 & 1.21 & bake & 4 & 3.38 & 0.75 & 1.00 & 0.00 \\
\hline bang & 4 & 2.62 & 1.13 & 2.00 & 1.02 & baste & 5 & 1.27 & 0.45 & 1.31 & 0.68 \\
\hline barf & 4 & 2.65 & 1.02 & 1.77 & 0.65 & bean & 4 & 3.08 & 1.13 & 1.04 & 0.20 \\
\hline bitch & 5 & 4.00 & 0.94 & 3.88 & 0.95 & beer & 4 & 3.88 & 0.95 & 1.69 & 0.79 \\
\hline boobs & 5 & 3.96 & 1.00 & 2.62 & 1.06 & broth & 5 & 2.38 & 1.20 & 1.00 & 0.00 \\
\hline chink & 5 & 1.81 & 1.20 & 4.12 & 1.07 & cake & 4 & 3.27 & 0.83 & 1.00 & 0.00 \\
\hline clit & 4 & 2.04 & 1.28 & 4.31 & 1.16 & chef & 4 & 2.50 & 1.24 & 1.00 & 0.00 \\
\hline cock & 4 & 2.62 & 1.24 & 4.23 & 0.86 & chips & 5 & 3.62 & 1.36 & 1.00 & 0.00 \\
\hline crap & 4 & 4.42 & 0.86 & 2.35 & 0.98 & chop & 4 & 2.69 & 1.23 & 1.12 & 0.43 \\
\hline cum & 3 & 2.58 & 1.24 & 4.15 & 1.12 & cook & 4 & 4.12 & 1.03 & 1.00 & 0.00 \\
\hline cunt & 4 & 1.88 & 1.11 & 4.15 & 1.26 & corn & 4 & 2.92 & 1.02 & 1.00 & 0.00 \\
\hline dick & 4 & 2.92 & 1.32 & 3.85 & 1.05 & dice & 4 & 2.27 & 1.00 & 1.04 & 0.20 \\
\hline douche & 6 & 2.00 & 1.30 & 3.19 & 1.36 & dill & 4 & 1.35 & 0.69 & 1.58 & 0.90 \\
\hline dyke & 4 & 2.27 & 1.19 & 3.77 & 1.14 & dish & 4 & 3.92 & 1.23 & 1.00 & 0.00 \\
\hline fag & 3 & 3.00 & 1.20 & 3.92 & 1.26 & fig & 3 & 1.77 & 1.11 & 1.08 & 0.27 \\
\hline fart & 4 & 3.54 & 1.10 & 2.08 & 0.93 & flour & 5 & 2.88 & 1.31 & 1.00 & 0.00 \\
\hline fuck & 4 & 4.31 & 0.88 & 4.54 & 0.81 & fork & 4 & 4.12 & 1.18 & 1.00 & 0.00 \\
\hline jizz & 4 & 1.81 & 1.23 & 3.27 & 1.48 & jam & 3 & 2.50 & 0.95 & 1.04 & 0.20 \\
\hline piss & 4 & 3.69 & 1.09 & 2.73 & 1.00 & pear & 4 & 2.19 & 0.75 & 1.00 & 0.00 \\
\hline porn & 4 & 3.23 & 1.07 & 2.96 & 1.25 & pies & 4 & 3.08 & 1.09 & 1.00 & 0.00 \\
\hline prick & 5 & 2.58 & 1.21 & 2.88 & 1.07 & plate & 5 & 4.23 & 0.99 & 1.00 & 0.00 \\
\hline puke & 4 & 2.88 & 1.21 & 2.04 & 0.77 & pour & 4 & 3.73 & 1.04 & 1.00 & 0.00 \\
\hline queer & 5 & 3.12 & 0.91 & 3.69 & 1.19 & quiche & 6 & 1.62 & 0.90 & 1.19 & 0.49 \\
\hline rape & 4 & 2.85 & 1.16 & 2.96 & 1.31 & rice & 4 & 3.81 & 1.10 & 1.00 & 0.00 \\
\hline shit & 4 & 4.58 & 0.81 & 3.46 & 1.21 & salt & 4 & 4.00 & 0.98 & 1.00 & 0.00 \\
\hline slut & 4 & 3.77 & 1.24 & 3.58 & 1.17 & snack & 5 & 4.08 & 1.06 & 1.04 & 0.20 \\
\hline snatch & 6 & 2.31 & 1.01 & 2.08 & 1.29 & soup & 4 & 3.46 & 1.24 & 1.00 & 0.00 \\
\hline spic & 4 & 1.35 & 0.89 & 2.77 & 1.56 & steak & 5 & 3.19 & 1.13 & 1.00 & 0.00 \\
\hline suck & 4 & 4.08 & 0.89 & 2.27 & 1.12 & stew & 4 & 2.23 & 1.18 & 1.04 & 0.20 \\
\hline tit & 3 & 2.81 & 1.41 & 3.58 & 0.99 & tea & 3 & 3.92 & 0.89 & 1.00 & 0.00 \\
\hline turd & 4 & 2.27 & 1.31 & 2.46 & 1.07 & thyme & 5 & 1.27 & 0.60 & 1.19 & 0.49 \\
\hline twat & 4 & 1.35 & 0.85 & 2.58 & 1.58 & toast & 5 & 3.38 & 0.90 & 1.00 & 0.00 \\
\hline whore & 5 & 3.65 & 0.89 & 3.73 & 1.19 & wheat & 5 & 3.08 & 1.20 & 1.00 & 0.00 \\
\hline Mean & 4.21 & 2.96 & & 3.17 & & Mean & 4.24 & 2.97 & & 1.08 & \\
\hline$S D$ & 0.73 & 0.90 & & 0.79 & & $S D$ & 0.70 & 0.90 & & 0.17 & \\
\hline
\end{tabular}

Received February 23, 2005 